\title{
Mind the gap: TB trends in the USA and the UK, 2000-2011
}

\author{
Chimeremma D Nnadi, ${ }^{1,2}$ Laura F Anderson, ${ }^{3}$ Lori R Armstrong, ${ }^{2}$ Helen R Stagg, ${ }^{4}$ \\ Debora Pedrazzoli, ${ }^{5}$ Robert Pratt, ${ }^{2}$ Charles M Heilig, ${ }^{2}$ Ibrahim Abubakar, ${ }^{3,4}$ \\ Patrick K Moonan²
}

\begin{abstract}
- Additional material is published online only. To view please visit the journal online (http://dx.doi.org/10.1136/ thoraxjn-2015-207915).
\end{abstract}

${ }^{1}$ Epidemic Intelligence Service, Centers for Disease Control and Prevention, Atlanta, Georgia, USA

${ }^{2}$ Division of Tuberculosis Elimination, Centers for Disease Control and Prevention, Atlanta, Georgia, USA

${ }^{3}$ Tuberculosis Section, Public Health England, London, UK ${ }^{4}$ Research Department of Infection and Population Health, University College London, London, UK ${ }^{5}$ TB Modelling Group, TB Centre and CMMID, London School of Hygiene and Tropical Medicine, Faculty of Epidemiology and Population Health, London, UK

\section{Correspondence to} Dr Patrick K Moonan, Division of Global HIV and Tuberculosis, Centers for Disease Control and Prevention, 1600 Clifton Rd NE, Atlanta GA 30336, USA; pmoonan@cdc.gov

IA and PKM contributed equally.

Received 9 October 2015 Revised 17 December 2015

Accepted 5 January 2016

Published Online First

23 February 2016

\section{ABSTRACT \\ Background TB remains a major public health} concern, even in low-incidence countries like the USA and the UK. Over the last two decades, cases of TB reported in the USA have declined, while they have increased substantially in the UK. We examined factors associated with this divergence in TB trends between the two countries.

Methods We analysed all cases of TB reported to the US and UK national TB surveillance systems from 1 January 2000 through 31 December 2011. Negative binominal regression was used to assess potential demographic, clinical and risk factor variables associated with differences in observed trends.

Findings A total of 259609 cases were reported. From 2000 to 2011, annual TB incidence rates declined from 5.8 to 3.4 cases per 100000 in the USA, whereas in the UK, TB incidence increased from 11.4 to 14.4 cases per 100000 . The majority of cases in both the USA (56\%) and the UK (64\%) were among foreign-born persons. The number of foreign-born cases reported in the USA declined by 15\% (7731 in 2000 to 6564 in 2011) while native-born cases fell by $54 \%$ (8442 in 2000 to 3883 in 2011). In contrast, the number of foreign-born cases reported in the UK increased by $80 \%$ (3380 in 2000 to 6088 in 2011), while the number of native-born cases remained largely unchanged (2158 in 2000 to 2137 in 2011). In an adjusted negative binomial regression model, significant differences in trend were associated with sex, age, race/ethnicity, site of disease, HIV status and previous history of TB $(p<0.01)$. Among the foreign-born, significant differences in trend were also associated with time since UK or US entry $(p<0.01)$.

Interpretation To achieve TB elimination in the UK, a re-evaluation of current TB control policies and practices with a focus on foreign-born are needed. In the USA, maintaining and strengthening control practices are necessary to sustain the progress made over the last 20 years.

\section{INTRODUCTION}

CrossMark

To cite: Nnadi CD, Anderson LF, Armstrong LR, et al. Thorax 2016;71: 356-363.
The USA and UK are low TB incidence countries, defined as countries with an annual TB incidence rate of $<20$ cases per 100000 population. ${ }^{12}$ Both countries are considered high income nations, ${ }^{3}$ with good population health indicators. ${ }^{4}{ }^{5}$ In the last decade, the USA and UK ranked first and fourth, respectively, on a list of nations with largest

\section{Key messages}

What is the key question?

- Why are TB case rates decreasing in the USA but increasing in the UK?

What is the bottom line?

- During 2000-2011, the number of foreign-born TB cases in the UK increased by $80 \%$ whereas in the USA the number of foreign-born TB cases had decreased by $15 \%$.

\section{Why read on?}

- In this study, we examined trends in the number of reported TB cases and incidence rates between the USA and the UK with a focus on the demographic and clinical characteristics that may help explain the differing trends between these two countriesand therefore, inform future TB prevention and control efforts in both countries.

numbers of migrants. ${ }^{6}$ On average, one million immigrants per annum settled in the USA and 400000 settled in the UK. ${ }^{6}$

In spite of similarities in economic, population health and migration indices, trends in annual reported TB case counts and incidence rates in the USA and the UK have been diverging. Both countries experienced parallel declines through the late 1980s. In 1992, both countries reported approximately $10 \mathrm{~TB}$ cases per $100000 .^{78}$ Since then, the USA has reported 22 consecutive years of annual TB decline, culminating in the lowest reported TB incidence rate in its history of 3.0 cases per 100000 in $2013 .^{8}$

In contrast, TB rates in the UK increased steadily over the last 20 years with a peak of 14.4 cases per 100000 recorded in $2009,{ }^{7}$ which declined to 12.3 per 100000 in $2013 .^{7}$ The factors associated with this divergence in trends are not clear. Several studies attribute rising TB rates to a combination of an increased number of TB cases and reactivation of latent infection among immigrants in UK. ${ }^{9-12}$ In the USA, the decline in annual TB rates has been attributed to ongoing improvements in TB control practices and a decline in incidence among the foreign-born. ${ }^{8}$ 13-15

In this study, we examined trends in the number of reported TB cases and incidence rates between 
the USA and the UK from 2000 through 2011 with a focus on the demographic and clinical characteristics that may help explain the differing trends between these two countries-and therefore, inform future TB prevention and control efforts in both countries.

\section{METHODS}

We included all TB cases reported in the USA and the UK from 1 January 2000 through 31 December 2011. TB cases in the USA were reported to the US National Tuberculosis Surveillance System from all 50 US states and the District of Columbia. TB cases in the UK were reported to the Enhanced Tuberculosis Surveillance System. Using standardised case reporting definitions, demographic, clinical and social risk factor data were collected on each patient as part of routine surveillance as described elsewhere. ${ }^{16}{ }^{17} \mathrm{~TB}$ incidence (case) rates were calculated by dividing the annual reported number of TB cases by the appropriate mid-year population estimate obtained from the Intercensal Estimates of the Resident Population of the USA, ${ }^{18}$ the US Current Population Survey ${ }^{19}$ or the UK Office of National Statistics. ${ }^{20}$ Race/ethnicity groups from the USA and the UK were recoded into four groups to harmonise classification systems between countries: Asian, black, white and other. Hispanic, Native Hawaiian/Alaska Native, American Indian and mixed race groups in the USA were recorded as 'Other'. In the UK, Indian, Pakistani, Bangladeshi and Chinese race/ethnicity groups were recorded as Asian; black African, black Caribbean and black other groups were recorded as black; and the mixed race group was retained as 'Other'. HIV test result data in the USA were available as negative, positive, indeterminate, unknown, refused and test done but results unknown. In the UK, HIV data were available only as a dichotomous variable; positive and not known to be positive. Therefore, HIV for the USA was dichotomised accordingly to allow for direct comparison between the two countries. Among foreign-born, time from US or UK entry to TB diagnosis was categorised into four classes: $<2$ years, $2-5$ years, $6-9$ years and $\geq 10$ years. Multidrug-resistant TB (MDR-TB) was defined as antituberculosis drug resistance to at least isoniazid and rifampicin.

\section{Statistical analysis}

We used JoinPoint with Monte Carlo permutation significance testing $^{21}$ to estimate the annual per cent change (APC) in TB case rates over time and the year significant rate changes occurred. To estimate the trends in TB case counts, we used negative binomial regression analysis to model the APC for the different population subgroups. ${ }^{21-25}$ Our final model included the following variables: place of birth, sex, age group, previous history of TB, site of disease, race/ethnicity, HIV status and time since entry among US or UK foreign-born. We conducted a stratified regression analysis with a three-way interaction model including the number of cases by report year in each reporting country and each of several variables under consideration, such as site of disease (exclusively pulmonary, exclusively extrapulmonary or both) and place of birth (US or UK foreign-born, US or UK native-born). Additional negative binomial models were used to assess trends by time from entry to TB diagnosis among the foreign-born and HIV coinfection. We calculated empirical estimates of annualised per cent change ((case count for 2011/ case count for 2000) $)^{(1 / 11)} \times 100$ ) for comparison with model estimates. Because only non-identifiable, routinely collected surveillance data were used, the study did not require human subjects review.

\section{RESULTS}

Demographic and selected clinical characteristics

A total of 259609 TB cases, including 163837 cases in the USA and 95772 cases in the UK, were reported from 2000 through 2011 (table 1). In the USA, 62\% of cases were male, the median age was 44 years ( $I Q R=29-60$ years); half of all reported cases were in the oldest age group (aged 45 years and older). The proportion of reported cases by race/ethnicity was as follows: Asian, 24\%; black, 28\%; white, 18\% and 'Other', $30 \%$ (table 1). The vast majority (93\%) of cases of 'Other' were persons of Hispanic ethnicity. Nearly $70 \%$ of the cases had exclusively pulmonary disease, $21 \%$ had exclusively extrapulmonary disease and $9 \%$ had both. Nearly $8 \%$ of the cases were known to be HIV positive at the time of TB diagnosis.

In the UK, $55 \%$ of cases were male, the median age was 36 years ( $\mathrm{IQR}=26-53$ years); the majority of cases $(59 \%)$ were in 15-44 years age group. The approximate proportions of reported cases by race/ethnicity were as follows: Asian, 40\%; black, 23\%; white, $24 \%$ and 'Other' or unknown $13 \%$ (table 1$)$. Less than half $(47 \%)$ of the cases had exclusively pulmonary disease, nearly $44 \%$ were exclusively extrapulmonary and $9 \%$ had both. Approximately, 5\% of the cases were known to be HIV positive at the time of TB reporting.

\section{Trends in TB incidence rate}

There were significant trend differences in reported TB cases between the USA and the UK during 2000-2011 (figure 1). In the USA, TB case counts declined from 16309 to 10 528, while rates declined from 5.8 to 3.4 cases per 100000 . Significant declines in overall US TB incidence rates were observed during 2000-2007 ( $\mathrm{APC}=-3.7, \mathrm{p}<0.001$ ), followed by more rapid declines during 2008-2011 ( $\mathrm{APC}=-6.6, \mathrm{p}<0.001$ ). In the UK, annual TB case counts increased from 6724 to 8963 and incidence rates increased from 11.4 to 14.4 cases per 100000 . We found significant increases in overall UK rates during 2000$2005(\mathrm{APC}=+3.4, \mathrm{p}<0.001)$ followed by a period of relatively stable rates during 2006-2011 (APC $=+0.2, \mathrm{p}=0.78)$.

\section{Trends in TB incidence rates-native-born persons}

In 2000, US native-born case rates (3.5 per 100000$)$ were comparable with UK native-born case rates (4.2 per 100000$)$ (figure 2). From 2000 through 2011, US native-born rates fell by $57 \%$ with the greatest rate of decline observed during 2000 2002 (APC $=-9.1, \mathrm{p}<0.001)$. Further declines were observed during 2003-2006 (APC $=-5.6, \mathrm{p}<0.001)$ and 2007-2011 $(\mathrm{APC}=-8.3, \mathrm{p}<0.001)$. In contrast, UK native-born incidence rates remained unchanged over the same period $(\mathrm{APC}=0.00$, $\mathrm{p}=0.91$ ).

\section{Trends in TB incidence rates-foreign-born persons}

A decline in case rates (from 27.1 to 17.1 per 100000 ) was observed among the US foreign-born during 2000-2011 ( $\mathrm{APC}=-4.3, \mathrm{p}<0.001$ ) (figure 3 ). The country of birth varied greatly among foreign-born TB cases diagnosed in the USA (number of known birth countries=209). Persons with TB born in five countries (Mexico, Philippines, Vietnam, India and China) made up $55.2 \%$ of all foreign-born cases in the USA. Annualised TB case counts and incidence rates among foreignborn persons by country of birth in the USA are presented in online supplementary table S1. Among the UK foreign-born, there was an increase in case rates from 77.2 to 98.6 per 100000 during 2000-2005 ( $\mathrm{APC}=+6.0, \mathrm{p}<0.001)$ followed by a decline to 83.6 per 100000 in 2011 (APC $=-2.2$, 
Table 1 Demographic and selected clinical characteristics of persons with reported TB, case counts-the UK and the USA, 2000-2011

\begin{tabular}{|c|c|c|}
\hline Characteristic & $\begin{array}{l}\text { UK } \\
\text { Case counts } \\
\mathrm{n}(\%)\end{array}$ & $\begin{array}{l}\text { USA } \\
\text { Case counts } \\
\mathbf{n}(\%)\end{array}$ \\
\hline Case count, all & $95772(100)$ & $163837(100)$ \\
\hline Age, median (IQR) & $36(26-53)$ & $44(29-60)$ \\
\hline \multicolumn{3}{|l|}{ Sex } \\
\hline Male & $52938(55.3)$ & 100765 (61.5) \\
\hline Female & $42590(44.5)$ & $63041(38.5)$ \\
\hline Missing or unknown & $244(0.3)$ & $31(0.02)$ \\
\hline \multicolumn{3}{|l|}{ Age group, years } \\
\hline $00-14$ & $5139(5.4)$ & $9780(6.0)$ \\
\hline $15-44$ & $56741(59.2)$ & $72895(44.5)$ \\
\hline$\geq 45$ & $33892(35.4)$ & $81144(49.5)$ \\
\hline Missing or unknown & $18(0.0)$ & $18(0.0)$ \\
\hline \multicolumn{3}{|l|}{ Origin of birth } \\
\hline Native-born & $25966(27.1)$ & 71704 (43.7) \\
\hline Foreign-born & $61012(63.7)$ & $91679(56.0)$ \\
\hline Missing or unknown & $8794(9.2)$ & $454(0.3)$ \\
\hline $\begin{array}{l}\text { Per cent of cases among the foreign-born } \\
(2000)^{*}\end{array}$ & 61 & 47 \\
\hline $\begin{array}{l}\text { Per cent of cases among the foreign-born } \\
(2011)^{*}\end{array}$ & 74 & 63 \\
\hline \multicolumn{3}{|l|}{ Race/ethnicity } \\
\hline Asian & $37977(39.7)$ & $39723(24.2)$ \\
\hline Black & $22194(23.2)$ & $45021(27.5)$ \\
\hline White & $22705(23.7)$ & $30013(18.3)$ \\
\hline Other & $8676(9.1)$ & $48548(29.6)$ \\
\hline Missing or unknown & $4220(4.4)$ & $532(0.3)$ \\
\hline \multicolumn{3}{|l|}{ History of previous TB } \\
\hline Yes & $6649(6.9)$ & $7984(4.9)$ \\
\hline No & $72882(76.1)$ & $153659(93.8)$ \\
\hline Missing or unknown & $16241(17.0)$ & $2194(1.3)$ \\
\hline \multicolumn{3}{|l|}{ Site of disease } \\
\hline Pulmonary only & $44923(46.9)$ & $115291(70.4)$ \\
\hline Extrapulmonary only & $41936(43.8)$ & $33832(20.7)$ \\
\hline Both & $8568(9.0)$ & $14621(8.9)$ \\
\hline Missing or unknown & $345(0.4)$ & $93(0.1)$ \\
\hline \multicolumn{3}{|l|}{ HIV status } \\
\hline Positive & $4679(4.9)$ & $12498(7.6)$ \\
\hline Not known to be positive & $91093(95.1)$ & 151339 (92.4) \\
\hline \multicolumn{3}{|l|}{ MDR-TB } \\
\hline Yes & $593(1.1)$ & $1524(1.2)$ \\
\hline No & $52959(97.9)$ & $123011(98.3)$ \\
\hline Unknown & $572(1.1)$ & $666(0.5)$ \\
\hline \multicolumn{3}{|l|}{ Top five countries of foreign birth* } \\
\hline Mexico & - & $21674(23.7)$ \\
\hline Philippines & - & $10206(11.2)$ \\
\hline Vietnam & - & $7212(7.9)$ \\
\hline India & $14178(24.1)$ & $6897(7.5)$ \\
\hline China & - & $4579(5.0)$ \\
\hline Pakistan & $10421(17.8)$ & - \\
\hline Somalia & $6033(10.3)$ & - \\
\hline Zimbabwe & $2508(4.3)$ & - \\
\hline Bangladesh & $2456(4.2)$ & - \\
\hline \multicolumn{3}{|l|}{ Time since entry (foreign-born) } \\
\hline$<2$ years & $13551(22.7)$ & $23149(25.4)$ \\
\hline $2-5$ years & 14871 (24.9) & 17984 (19.7) \\
\hline $6-9$ years & 7744 (13.0) & 13031 (14.3) \\
\hline
\end{tabular}

Table 1 Continued

\begin{tabular}{|c|c|c|}
\hline Characteristic & $\begin{array}{l}\text { UK } \\
\text { Case counts } \\
\text { n (\%) }\end{array}$ & $\begin{array}{l}\text { USA } \\
\text { Case counts } \\
\text { n (\%) }\end{array}$ \\
\hline$\geq 10$ years & 14292 (23.9) & 31908 (34.9) \\
\hline Missing or unknown & 9235 (15.5) & $5256(5.8)$ \\
\hline $\begin{array}{l}\text { Median time in years from entry to } \\
\text { diagnosis (IQR) }\end{array}$ & $4(1-13)$ & $6(1-17)$ \\
\hline
\end{tabular}

$\mathrm{p}<0.001)$. The country of birth also varied among foreign-born TB cases diagnosed in the UK (number of known birth countries=206). Five countries (India, Pakistan, Bangladesh, Somalia and Zimbabwe) contributed $61 \%$ of all foreign-born cases. Annualised TB case counts and incidence rates among foreignborn persons by country of birth in the UK are presented in online supplementary table S2.

\section{Trend analysis of TB case counts}

A total of 248005 cases including 162763 (99\%) cases from the USA and $85242(90 \%)$ cases from the UK were included in the analysis. The rest were excluded due to missing variables. Sex, race/ethnicity, age group, site of disease, previous TB history, HIV status and time from entry to disease diagnosis among the foreign-born were significantly associated with differences in trend between the USA and the UK (table 2).

Age group was associated with divergent TB incidence trends between the USA and the UK. In the USA, case counts declined across all nativity and age groups, except in foreign-born persons in the 45 years and older age group, which remained unchanged. In the UK, increases were observed across all nativity and age groups, except among native-born 45 years and older group where a decline was observed.

Race/ethnicity was associated with differences in TB incidence trends. There were substantial declines in TB case counts across all race groups, with the exception of the US-born Asian group, where an increase was observed. In contrast, declines in case counts in the UK were limited to the native-born white group.

Site of disease was associated with differences in overall TB trends. In the USA, there were declines in the number of exclusively pulmonary and exclusively extrapulmonary $\mathrm{TB}$ cases in both foreign-born and native-born, with the exception of a slight $(2 \%)$ increase among foreign-born cases diagnosed with both pulmonary and extrapulmonary disease. In the UK, cases of exclusively extrapulmonary $\mathrm{TB}$ more than doubled in number among the foreign-born. There was a small decline $(-1.0$ APC) in the number of native-born pulmonary cases, but broad increases in the number of cases with both extrapulmonary and pulmonary disease presentation among both foreignborn and native-born groups.

HIV status was associated with changes in TB incidence trends. Coinfected TB-HIV case counts declined from peaks observed through the mid-2000s (highest annual count $=485$ (7\% among all cases) in 2004) in the UK. In the USA, there were significant and consistent declines in TB-HIV case counts from 2000 through 2011.

Among the foreign-born, time from US or UK entry to TB diagnosis was associated with diverging TB trends. While the number of cases diagnosed within 2 years of entry fell by $44 \%$ 


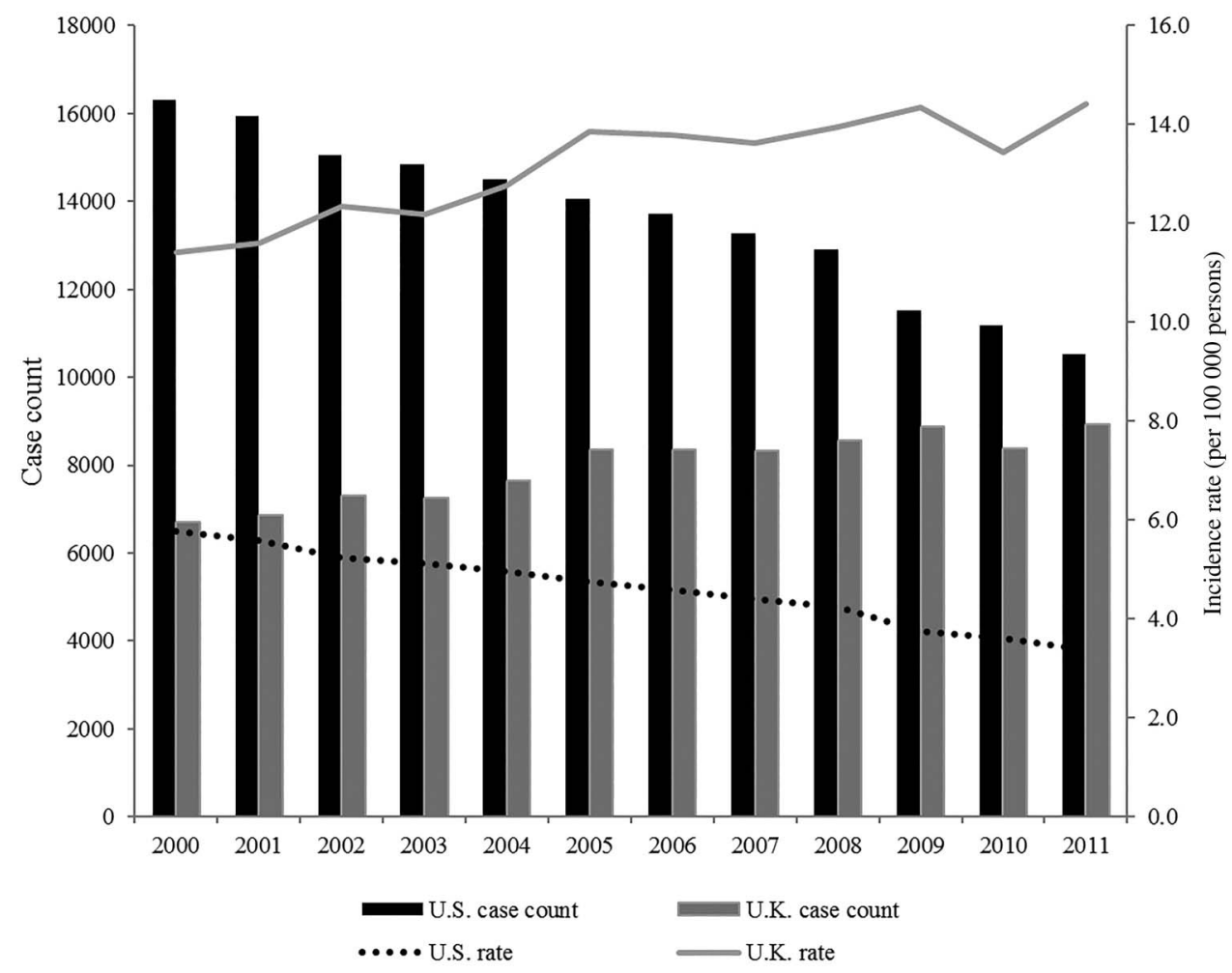

Figure 1 TB trends - the UK and the USA, 2000-2011.

in the USA, it rose nearly $59 \%$ in the UK. TB case counts increased among all UK foreign-born time since arrival categories, with the largest increases observed among persons diagnosed within 2-5 years (150\%) and 6-9 years (183\%) from arrival. In contrast, in the USA, declines in case counts were observed across all foreign-born cases with the exception of persons diagnosed after $>10$ years in the USA, in which a $10 \%$ increase was observed.

\section{DISCUSSION}

Our analysis describes the similarities and contrasts in TB trends between the UK and the USA. In both countries, the proportion of $\mathrm{TB}$ cases attributed to the foreign-born was on the rise, reflecting patterns observed in many immigrant-receiving countries. $^{26}{ }^{27}$ However, while TB among the foreign-born remains a major challenge in both countries, we observed striking contrasts in TB trends among both foreign-born and native-born.

Among the foreign-born, a significant divergence in TB trends was observed. This divergence may be explained in part by differences in migration patterns over the past decade. Differing migration patterns is of particular importance, given that in the first few years following arrival, foreign-born TB rates may approximate rates in originating regions of the world. ${ }^{28}$ While the largest proportion of US migrants in the last decade originated from Latin American countries with relatively low TB burden, ${ }^{1}{ }^{29}$ the UK recorded substantial increases in migration
Figure 2 TB trends among the native-born-the UK and the USA, 2000-2011.

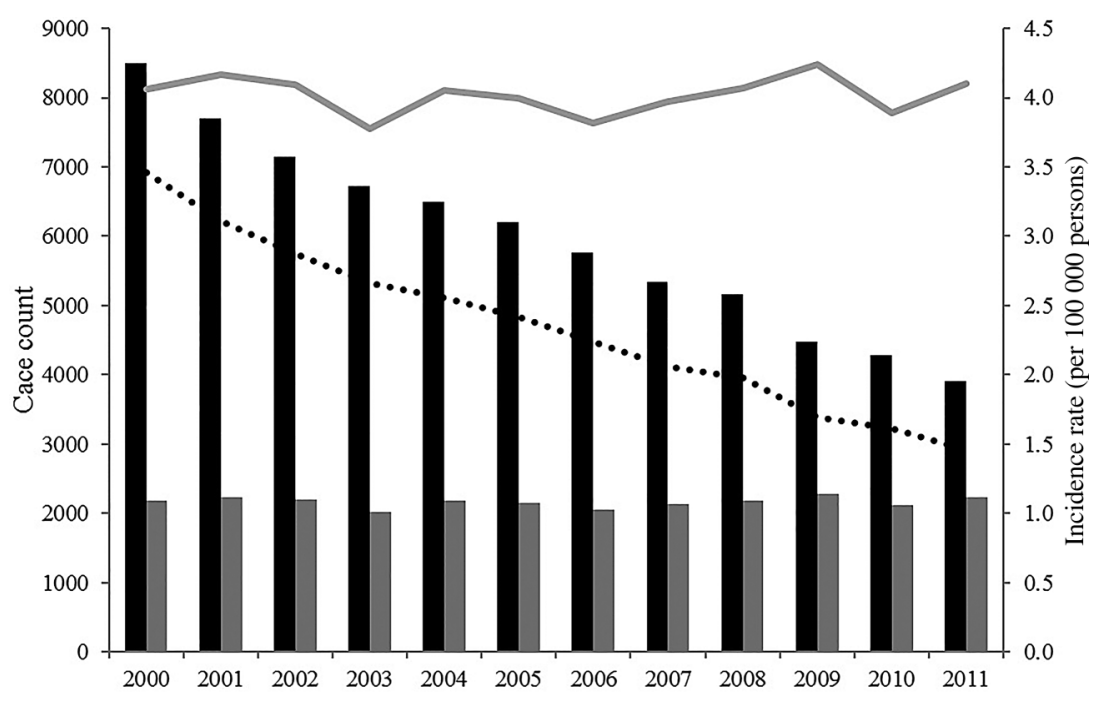



foreign-born-the UK and the USA, 2000-2011.
Figure 3 TB trends among the

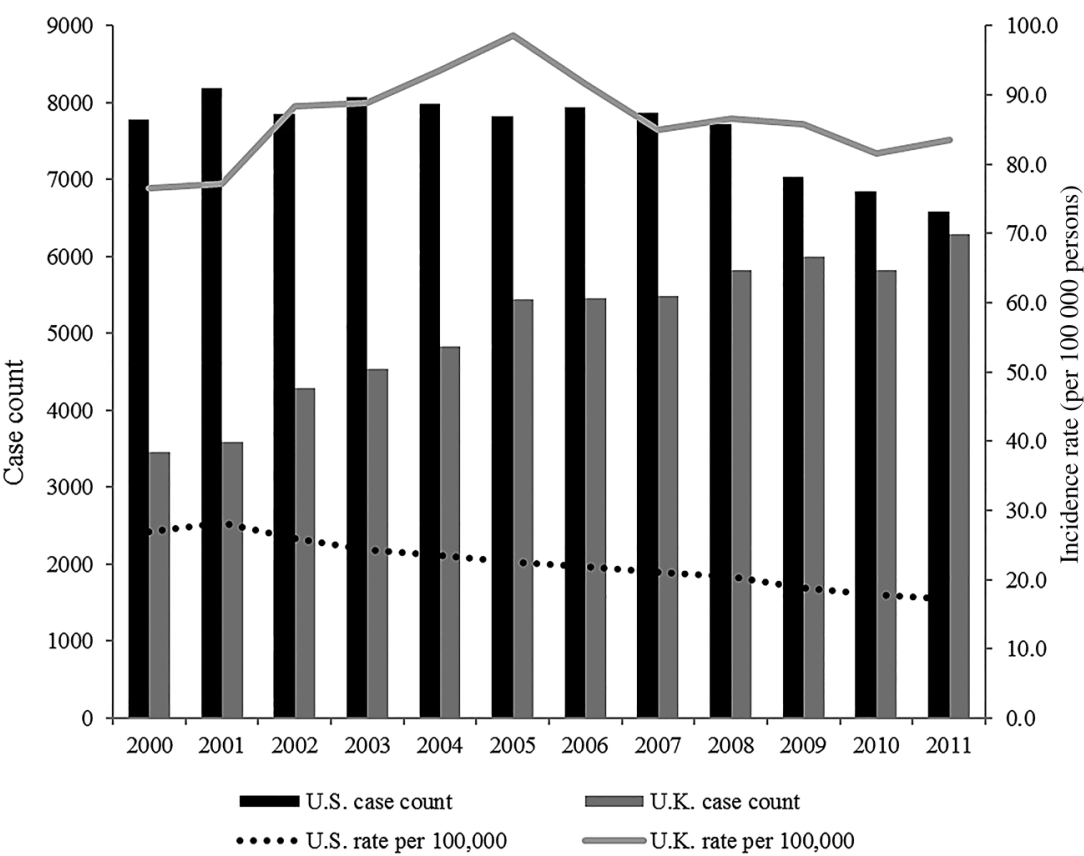

from South Asia and Sub-Saharan Africa-regions with some of the highest TB burdens in the world. ${ }^{1}{ }^{30}$ Some of the observed differences in trends may, therefore, be a reflection of the disparate burdens among major migrant groups in the USA relative to the UK. However, with few exceptions, the annualised TB incidence rates among foreign-born persons from the top 10 countries of birth now living in the USA tended to be lower than the rates in their countries of birth (see online supplementary table S1); while the annualised rates among foreign-born persons from the top 10 countries of birth now living in the UK were observed to match or exceed the rates in their countries of birth (see online supplementary table S2). For example, in 2011, persons from Mexico accounted for the largest proportion of TB cases among foreign-born persons in the USA. The incidences rate among these persons was 12 per 100000 (almost half the rate of persons living in Mexico (see online supplementary table S1). Whereas in the UK, persons from India accounted for the largest proportion of TB among foreign-born persons in the UK. The incidence rate among these persons was 253 per 100000 (36\% greater than the rate of persons living in India) (see online supplementary table S2). It is worth noting that in 2011, India-born persons and Philippine-born persons living in the USA had a lower TB incidence than their counterparts living in the UK and in the country of birth (27 vs 253 per 100000 ; 44 vs 91 per 100000 , respectively). This suggests that migration rates alone may not account for all differences and more complex factors could potentially be at play.

Differences in time from arrival to $\mathrm{TB}$ diagnosis were observed to significantly contribute to the diverging trends. Cases diagnosed within the first 2 years of arrival have distinct clinical and epidemiological importance, as they most likely represent imported disease. In a recent prearrival and postarrival evaluation of a cohort of US immigrants, $>80 \%$ of TB cases diagnosed within 1 year of receiving prearrival examination had radiological evidence of $\mathrm{TB}$ and represented imported $\mathrm{TB}$ cases. $^{31}$ Our study found that during 2000-2011, the number of US foreign-born cases diagnosed within 2 years of arrival declined by $44 \%$. In contrast, UK cases diagnosed within the same time frame increased by nearly $60 \%$, signifying increases in the number of TB cases in new UK arrivals. The observed decline in imported cases of TB among US migrants during this period may represent gains from the contemporaneous strengthening of US prearrival TB screening policy, transitioning from requiring an evidence of negative sputum smears to the more stringent standard of negative sputum culture results, for all intending US immigrants. ${ }^{15} 27$ But it may also reflect diminishing TB burdens in key US immigrant-originating countries. ${ }^{1} 32$ In the UK, TB screening practices during this period, in contrast, was largely limited to chest X-ray-based screening of selected migrants at two major airports, as well as screening of a smaller number of refugees and asylum seekers already in the country. The increases in cases among UK recent arrivals may thus represent a large number that could have been prevented through a more effective prearrival screening programme. Interestingly, recent data from Public Health England suggests rates in the UK are now declining due to changes in source countries of migrants as well as implementation of a pre-entry screening programme similar to the US model which prevented $>400$ cases in 2014 (PHE 2015 TB Annual Report).

Results from this study and others, where the majority of foreign-born cases may represent reactivation of latent TB infection (LTBI) acquired prior to migration, ${ }^{31} 33$ highlight the limitation of current approaches to TB prevention in which LTBI testing and treatment strategies have yet to be fully implemented. ${ }^{34} 35$ Overall, UK foreign-born cases had shorter (4 years) median time from entry to diagnosis compared with US cases (6 years). Whether this shorter time to diagnosis in UK immigrants indicates a more rapid progression to disease, a higher burden of disease in the first year from entry time, or increased disease transmission within the UK are points worthy of further inquiry.

In contrast to US foreign-born, UK foreign-born had a twofold increase in exclusively extrapulmonary cases. Potential ity to extrapulmonary disease especially among key UK ethnic groups. ${ }^{36}$ In the setting of a relatively low culture case confirmation, this trend may also represent possible excess clinical diagnoses of extrapulmonary $\mathrm{TB}$ in the UK population. It is explanations for this increase may include a selective susceptibil- 
Table 2 APC in TB case counts-the USA and the UK, 2000-2011 $(n=248005)$

\begin{tabular}{|c|c|c|c|c|c|c|c|c|}
\hline \multirow[b]{3}{*}{ Characteristic } & \multicolumn{4}{|l|}{ UK } & \multicolumn{4}{|l|}{ USA } \\
\hline & \multicolumn{2}{|c|}{ Case count } & \multicolumn{2}{|l|}{ APC } & \multicolumn{2}{|c|}{ Case count } & \multicolumn{2}{|l|}{ APC } \\
\hline & 2000 & 2011 & $\begin{array}{l}\text { Empirical } \\
\text { estimate* }\end{array}$ & $\begin{array}{l}\text { Model-based } \\
(95 \% \mathrm{Cl}) \dagger\end{array}$ & 2000 & 2011 & $\begin{array}{l}\text { Empirical } \\
\text { estimate* }\end{array}$ & $\begin{array}{l}\text { Model-based } \\
(95 \% \mathrm{Cl}) \dagger\end{array}$ \\
\hline \multicolumn{9}{|l|}{ Place of birth } \\
\hline Foreign-born & 3380 & 6088 & 5.5 & $5.2(4.4$ to 6.0$)$ & 7731 & 6546 & -1.5 & $-1.6(-2.3$ to -0.8$)$ \\
\hline Native-born & 2158 & 2137 & -1.0 & $-0.2(-0.9$ to 0.6$)$ & 8442 & 3883 & -6.8 & $-6.4(-7.1$ to -5.7$)$ \\
\hline \multicolumn{9}{|l|}{ Sex } \\
\hline Foreign-born, female & 1612 & 2605 & 4.5 & 4.4 (3.6 to 5.3 ) & 3105 & 2737 & -1.1 & $-1.4(-2.1$ to -0.6$)$ \\
\hline Foreign-born, male & 1768 & 3483 & 6.4 & 5.8 (5.0 to 6.6 ) & 4626 & 3809 & -1.8 & $-1.7(-2.4$ to -0.9$)$ \\
\hline Native-born, female & 906 & 900 & -0.1 & $0.2(-0.7$ to 1.1$)$ & 2943 & 1332 & -7.0 & $-6.5(-7.3$ to -5.7$)$ \\
\hline Native-born, male & 1252 & 1237 & -0.1 & $-0.4(-1.2$ to 0.5$)$ & 5499 & 2551 & -6.7 & $-6.4(-7.1$ to -5.7$)$ \\
\hline \multicolumn{9}{|l|}{ Race/ethnicity } \\
\hline Foreign-born, white & 233 & 278 & 1.6 & 2.9 (1.4 to 4.5$)$ & 536 & 334 & -4.2 & $-4.1(-5.4$ to -2.8$)$ \\
\hline Foreign-born, black & 914 & 1514 & 4.7 & 3.4 (2.2 to 4.7$)$ & 1045 & 870 & -1.7 & $-1.8(3.0$ to -0.6$)$ \\
\hline Foreign-born, Asian & 1876 & 3473 & 5.8 & 6.0 (4.9 to 7.3 ) & 3218 & 3007 & -0.6 & $-0.6(-1.7$ to 0.5$)$ \\
\hline Foreign-born, other & 357 & 823 & 7.9 & 6.4 (5.0 to 7.8$)$ & 2932 & 2335 & -2.0 & $-2.1(-3.2$ to -1.0$)$ \\
\hline Native-born, white & 1584 & 1345 & -1.5 & $-1.8(-2.9$ to -0.7$)$ & 3097 & 1324 & -7.4 & $-7.3(-8.3$ to -6.2$)$ \\
\hline Native-born, black & 175 & 234 & 2.7 & 4.1 (2.5 to 5.8$)$ & 4095 & 1531 & -8.6 & $-7.9(-8.9$ to -6.8$)$ \\
\hline Native-born, Asian & 368 & 475 & 2.3 & 2.6 (1.2 to 4.0$)$ & 112 & 133 & 1.6 & $2.0(0.2$ to 3.9$)$ \\
\hline Native-born, other & 31 & 83 & 9.4 & $8.6(5.9$ to 11.3$)$ & 1138 & 895 & -2.2 & $-2.0(-3.2$ to -0.9$)$ \\
\hline \multicolumn{9}{|l|}{ Age group, years } \\
\hline Foreign-born, 0-14 & 97 & 133 & 2.9 & 0.8 (-0.9 to 2.5$)$ & 257 & 122 & -6.5 & $-6.3(-7.6$ to -4.9$)$ \\
\hline Foreign-born, 15-44 & 2146 & 4125 & 6.1 & $5.6(4.5$ to 6.5$)$ & 4262 & 3225 & -2.5 & $-2.5(-3.4$ to -1.6$)$ \\
\hline Foreign-born, $\geq 45$ & 1137 & 1830 & 4.4 & 4.6 (3.7 to 5.6 ) & 3212 & 3199 & 0.0 & $0.0(-0.9$ to 0.8$)$ \\
\hline Native-born, 0-14 & 228 & 247 & 0.7 & $1.0(-0.3$ to 2.4$)$ & 684 & 452 & -3.7 & $-3.5(-4.5$ to -2.5$)$ \\
\hline Native-born, 15-44 & 776 & 933 & 1.7 & $1.4(0.4$ to 2.4$)$ & 2874 & 1145 & -8.0 & $-7.4(-8.2$ to -6.5$)$ \\
\hline Native-born, $\geq 45$ & 1154 & 957 & -1.7 & $-1.7(-2.6$ to -0.7$)$ & 4884 & 2286 & -6.7 & $-6.4(-7.2$ to -5.6$)$ \\
\hline \multicolumn{9}{|l|}{ Site of disease } \\
\hline Foreign-born pulmonary & 1402 & 2038 & 3.5 & 2.5 (1.6 to 3.4$)$ & 5352 & 4242 & -2.1 & $-2.0(-2.8$ to -1.2$)$ \\
\hline Foreign-born extrapulmonary & 1666 & 3371 & 6.6 & 6.8 (5.9 to 7.7$)$ & 1768 & 1492 & -1.5 & $-1.5(-2.4$ to -0.7$)$ \\
\hline Foreign-born both & 312 & 679 & 7.3 & 7.3 (6.1 to 8.5$)$ & 611 & 812 & 2.6 & $2.0(1.0$ to 3.0$)$ \\
\hline Native-born pulmonary & 1448 & 1353 & -0.6 & $-1.0(-1.9$ to -0.1$)$ & 6376 & 2722 & -7.4 & $-6.9(-7.6$ to -6.1$)$ \\
\hline Native-born extrapulmonary & 571 & 628 & 0.9 & $1.2(0.1$ to 2.2$)$ & 1416 & 676 & -6.5 & $-5.9(-6.8$ to -5.0$)$ \\
\hline Native-born both & 139 & 156 & 1.1 & $2.4(0.8$ to 4.0$)$ & 650 & 485 & -2.6 & $-3.8(-4.8$ to -2.8$)$ \\
\hline \multicolumn{9}{|l|}{ Previous TB history } \\
\hline Foreign-born, yes & 250 & 362 & 3.4 & $5.1(-0.4$ to 11.0$)$ & 379 & 331 & -1.2 & $-1.5(-6.7$ to 4.1$)$ \\
\hline Foreign-born, no & 2796 & 5411 & 6.2 & $6.2(0.7$ to 12.0$)$ & 7308 & 6167 & -1.5 & $-1.8(-7.0$ to 3.7$)$ \\
\hline Foreign-born, unknown & 334 & 315 & -0.5 & $-2.4(-8.5$ to 4.2$)$ & 44 & 48 & 0.8 & 13.9 (7.8 to 20.3$)$ \\
\hline Native-born, yes & 223 & 121 & -5.4 & $-2.7(-7.8$ to 2.8$)$ & 463 & 176 & -8.4 & $-9.3(-14.1$ to -4.2$)$ \\
\hline Native-born, no & 1780 & 1927 & 0.7 & $0.5(-4.6$ to 5.9$)$ & 7912 & 3678 & -6.7 & $-6.3(-11.2$ to -1.2$)$ \\
\hline Native-born, unknown & 155 & 89 & -4.9 & $-4.4(-10.3$ to 1.9$)$ & 67 & 29 & -7.3 & -3.1 (8.2 to 2.4$)$ \\
\hline \multicolumn{9}{|l|}{ HIV statusł } \\
\hline Foreign-born, HIV positive & 223 & 245 & 0.9 & $-2.2(-3.8$ to -0.5$)$ & 508 & 333 & -3.8 & $-6.7(-8.2$ to -5.2$)$ \\
\hline $\begin{array}{l}\text { Foreign-born, HIV negative/ } \\
\text { unknown }\end{array}$ & 3290 & 5843 & 5.4 & 5.1 (3.7 to 6.6 ) & 7635 & 6213 & -1.9 & $-1.6(-2.9$ to -0.3$)$ \\
\hline Native-born, HIV positive & 27 & 30 & 1.0 & 2.9 (0.5 to 6.5$)$ & 895 & 336 & -8.5 & $-9.5(-10.9$ to -8.1$)$ \\
\hline Native-born, HIV negative/unknown & 2190 & 2107 & -0.2 & $0.2(-1.5$ to 1.2$)$ & 6765 & 3547 & -5.7 & $-6.0(-7.3$ to -4.8$)$ \\
\hline \multicolumn{9}{|l|}{ Time since entry (foreign-born)§ } \\
\hline$\leq 1$ year & 742 & 1179 & 4.3 & $1.3(-1.0$ to 3.6$)$ & 2224 & 1242 & -5.2 & $-5.1(-7.1$ to -2.9$)$ \\
\hline $2-5$ years & 566 & 1413 & 8.7 & 8.2 (5.6 to 10.8$)$ & 1407 & 1111 & -2.1 & $-2.5(-4.7$ to -0.3$)$ \\
\hline $6-9$ years & 390 & 1105 & 9.9 & $11.7(9.2$ to 14.1$)$ & 1144 & 976 & -1.4 & $-0.9(-3.0$ to 1.3$)$ \\
\hline$\geq 10$ years & 861 & 1583 & 5.7 & $4.7(2.5$ to 7.0$)$ & 2417 & 2654 & 0.9 & $0.9(-1.3$ to 3.1$)$ \\
\hline Unknown & 821 & 808 & -0.2 & - & 539 & 563 & 0.4 & - \\
\hline
\end{tabular}


imperative to note that while cases of exclusively extrapulmonary disease may not be associated with subsequent in-country transmission, they would likely evade detection by the chest $\mathrm{X}$-ray-based pre-entry screening programme currently in use for UK entrants.

Against the backdrop of an increasing proportion of foreignborn cases, TB prevention and control efforts in many lowincidence countries have shifted, appropriately, towards a focus on immigrant populations. ${ }^{8} 17$ Nevertheless, continued vigilance over TB control among the native-born in these countries is still needed. In the UK, the increasing incidence among the foreignborn has been the subject of a great deal of inquiry, ${ }^{36}{ }^{38}$ with little attention paid to the relatively unchanged indices among the native-born. Although the absolute numbers are smaller in comparison with cases among the foreign-born, our analysis raises concerns about the non-decline among the UK nativeborn, especially in the context of the rapid declines among the US native-born. Our analysis further suggests that the stagnating indices among the UK native-born are largely driven by increases among minority ethnic groups, although the underlying factors behind this trend are not entirely clear. Future research and interventions may focus on identifying and interrupting recent transmission, including increased household transmission from migrant parents to native-born children ${ }^{39} 40$ or transmission that occurs during extended visits to highburden TB countries. ${ }^{35} 41$

In prioritising public health action, both UK and USA have implemented a TB control strategy targeting three main population groups-intending immigrants prior to arrival, persons from high burden areas and at-risk native-born groups.

First, finding and treating TB cases among intending immigrants prior to arrival may prevent most TB cases. Although the USA has an established prearrival TB screening programme, current screening practices cover only refugees and persons seeking permanent residency and are primarily focused on active case finding, and not detection and treatment of LTBI. ${ }^{42}$ Similarly until very recently, only a select group of migrants from high-burden TB countries were screened on arrival in the UK. ${ }^{13}$ The UK has now adopted a prearrival immigrant screening programme that covers intending migrants, including students and other long-term visitors. ${ }^{38}$ In a similar way, in USA it would be important to evaluate the feasibility of expanding the current screening programme in order to further reduce potential cases among migrant groups not currently covered (eg, students and long-term visitors). ${ }^{43}$ Because a substantial proportion of future cases may emerge from activation of LTBI, ${ }^{30} 33$ the value and feasibility of identifying and treating persons with LTBI among intending immigrants may need further evaluation.

Second, given the high prevalence of reactivation disease among persons from high burden countries now living in the USA and UK, a well-coordinated system of identification, reporting and treatment of persons with latent TB should now be considered. In the past, concerns about the safety, cost and logistics of effectively implementing this programme was perceived as a major barrier. ${ }^{41}$ The availability of a safe and cost-effective 12 -dose regimen of weekly rifapentine plus isoniazid $(3 \mathrm{HP})^{44}$ could be used to develop and implement targeted LTBI testing and treatment, especially among postarrival migrant populations at the highest risk of disease progression.

Finally, rising or non-declining incidence among segments of the native-born population should be recognised as a potential threat to the gains made in TB control over the past few decades. In this regard, a greater understanding of the epidemiology and potential transmission pathways among native-born groups, including native-born Asians in the USA and all minority ethnic groups in the UK, is crucial. These efforts, as well as those that would shore up $\mathrm{TB}$ surveillance and prevention efforts among the entire population, will require greater investments in $\mathrm{TB}$ control. Therefore, increased funding for $\mathrm{TB}$ control activities at all levels must remain high policy priorities.

For this analysis, we recorded self-reported race and ethnicity groups to allow comparisons between the two countries. Doing so may have masked some important factors-including certain subpopulation groups driving the rate trends. Methods of HIV data collection, coding and linkage to the TB surveillance system were different and may have affected estimates of HIV coinfection in our analysis. For example, HIV testing data for most of the USA has detailed information that allows for estimating the coverage for HIV testing (49.8\% in 2000 and $82.5 \%$ in 2011). This calculation is not possible for the UK where only HIV positive cases are reported and the number tested negative are unknown.

During the period 2000-2011, TB trends declined in the USA and increased in the UK. While UK will benefit from a re-evaluation and improvement of its national TB control efforts, the USA will be well served by a continued improvement of existing control practices, especially those that focus on foreign-born persons and vulnerable native-born populations. It is our hope that lessons learnt from TB resurgence in the 1980s, which was preceded by a period of sustained decline, would help keep TB control funding at levels that optimally supports progress towards TB elimination in both countries. ${ }^{45}$

Acknowledgements We are grateful to our partners in the two countries who report tuberculosis to the US Centers for Disease Control and Prevention and Public Health England annually.

Contributors PKM and IA conceived the study. CDN, LRA, CMH, IA and PKM design the analytic plan. LFA, LRA, HS, DP and RP acquired the data. CDN, LRA and $C M H$ conducted the analysis. CDN, LFA, LRA, CMH, IA and PKM interpreted the data. CDN drafted the manuscript. CDN, LFA, LRA, HS, DRP, RP, CMH, IA and PKM provided critical revisions for important intellectual content. All authors approved the final version.

Funding Health Protection Agency, Centers for Disease Control and Prevention.

Disclaimer The findings and conclusions in this manuscript are those of the authors and do not necessarily represent the official position of the Centers for Disease Control and Prevention or the US Department of Health and Human Services.

Competing interests None declared.

Provenance and peer review Not commissioned; externally peer reviewed.

\section{REFERENCES}

1 World Health Organisation. Global Tuberculosis Report 2012. Geneva. 2013.

2 Broekmans JF, Migliori GB, Rieder HL, et al, World Health Organization, International Union Against Tuberculosis and Lung Disease, and Royal Netherlands Tuberculosis Association Working Group. European framework for tuberculosis control and elimination in countries with a low incidence. Recommendations of the World Health Organization (WHO), International Union Against Tuberculosis and Lung Disease (IUATLD) and Royal Netherlands Tuberculosis Association (KNCV) Working Group. Eur Respir J 2002;19:765-75.

3 The World Bank. GDP per capita (current US\$). 2014 (cited 14 December 2013). http://data.worldbank.org/indicator/NY.GDP.PCAP.CD

4 Reidpath DD, Allotey P. Infant mortality rate as an indicator of population health. J Epidemiol Commun H 2003;57:344-6.

5 Centers for Disease Control and Prevention. Infant Mortality (cited 25 January 2014). http://www.cdc.gov/reproductivehealth/maternalinfanthealth/infantmortality. htm

6 Organization for Economic Co-operation and Development. Population and Demography: International Migration Database. 2013 (cited 5 January 2014). http:// stats.oecd.org/Index.aspx?DatasetCode=MIG

7 Public Health England. Tuberculosis in the UK: 2014 report. London: Public Health England. 2014. https://www.gov.uk/government/uploads/system/uploads/ attachment_data/file/360335/TB_Annual_report_4_0_300914.pdf (accessed 5 Mar 2015). 
8 Centers for Disease Control and Prevention. Reported Tuberculosis in the United States, 2013. Atlanta, GA: U.S. Department of Health and Human Services, CDC 2014.

9 Gilbert RL, Antoine D, French CE, et al. The impact of immigration on tuberculosis rates in the United Kingdom compared with other European countries. Int I Tuberc Lung D 2009;13:645-51.

10 Lalvani A, Pareek M. Immigrant screening for TB: a missed opportunity to improve TB control in the United Kingdom. Pathog Glob Health 2012 106:5-7.

11 Pareek M, Watson JP, Ormerod LP, et al. Screening of immigrants in the UK for imported latent tuberculosis: a multicentre cohort study and cost-effectiveness analysis. Lancet Infect Dis 2011;11:435-44.

12 Pareek M, Abubakar I, White PJ, et al. Tuberculosis screening of migrants to low-burden nations: insights from evaluation of UK practice. Eur Respir J 2011;37:1175-82.

13 Pareek M, Baussano I, Abubakar I, et al. Evaluation of immigrant tuberculosis screening in industrialized countries. Emerging Infect Dis 2012;18:

1422-9.

14 Winston CA, Navin TR, Becerra JE, et al. Unexpected decline in tuberculosis cases coincident with economic recession-United States, 2009. BMC Public Health 2011;11:1471-2458.

15 Lowenthal P, Westenhouse J, Moore M, et al. Reduced importation of tuberculosis after the implementation of an enhanced pre-immigration screening protocol. Int J Tuberc Lung Dis 2011;15:761-6.

16 Centers for Disease Control and Prevention. Tuberculosis Surveillance Data Training Report of Verified Case of TB (RVCT). Self-Study Modules. Atlanta, GA: U.S. Department of Health and Human Services, CDC, 2009.

17 Public Health England. Tuberculosis in the UK 2013 Report. London, UK: Crown Publications, 2014.

18 United States Census Bureau. Intercensal Estimates of the Population of the United States (cited 24 March 2014). https://www.census.gov/popest/data/intercensal/ national

19 United States Census Bureau. Current Population Survey of the United States (cited 24 March 2014). http://www.census.gov/cps/

20 Office of National Statistics. Population Estimates for UK, England and Wales, Scotland and Northern Ireland. 2014 (cited 24 November 2014). http://www.ons. gov.uk/ons/rel/pop-estimate/

population-estimates-for-uk--england-and-wales--scotland-and-northern-ireland/ index.html

21 Kim HJ, Fay MP, Feuer EJ, et al. Permutation tests for join point regression with applications to cancer rates. Stat Med 2000;19:335-51.

22 Hilbe JM. Negative binomial regression. New York: Cambridge University Press, 2011.

23 Gardner W, Mulvey EP, Shaw EC. Regression analyses of counts and rates: Poisson, overdispersed Poisson, and negative binomial models. Psychol Bull 1995;118:392-404.

24 Coxe S, West SG, Aiken LS. The analysis of count data: a gentle introduction to Poisson regression and its alternatives. J Pers Assess 2009;91: 121-36.

25 National Cancer Institute. Surveillance Research. 2014 (cited 24 March 2014). http://surveillance.cancer.gov/joinpoint/aapc.html
26 Jensen $M$, Lau A, Langlois-Klassen $D$, et al. A population-based study of tuberculosis epidemiology and innovative service delivery in Canada. Int I Tuberc Lung Dis 2012;16:43-9, i.

27 Odone A, Tillmann T, Sandgren A, et al. Tuberculosis among migrant populations in the European Union and the European Economic Area. Eur J Public Health 2015;25:506-12.

28 Cain KP, Haley CA, Armstrong LR, et al. Tuberculosis among foreign-born persons in the United States-achieving tuberculosis elimination. Am J Resp Crit Care 2007; 175:75-9.

29 Greico EM, Thingholm TE, Larsen L, et al. The size, place of birth and geographic distribution of foreign-born population of the United States. Population Division Working Paper No. 96. Washington, D.C.: U.S. Census Bureau, 2012:17-19. (accessed 3 Feb 2106). https://www.census.gov/population/foreign/files/ WorkingPaper96.pdf

30 Office for National Statistics. Non-UK born population continues to rise. 2012 (cited 13 March 2014) http://www.ons.gov.uk/ons/rel/census/2011-census/key-statisticsfor-local-authorities-in-england-and-wales/sty-non-uk-born-population.html

31 Walter ND, Painter J, Parker M, et al. Persistent latent tuberculosis reactivation risk in United States immigrants. Am J Respir Crit Care Med 2014;189:88-95.

32 Baker BJ, Jeffries CD, Moonan PK. Decline in tuberculosis among Mexico-born persons in the United States, 2000-2010. Ann Am Thorac Soc 2014;7:7.

33 Ricks PM, Cain KP, Oeltmann JE, et al. Estimating the burden of tuberculosis among foreign-born persons acquired prior to entering the U.S., 2005-2009. PLOS ONE 2011;6:e27405.

34 Cain KP, Benoit SR, Winston CA, et al. Tuberculosis among foreign-born persons in the United States. JAMA 2008;300:405-12.

35 Dara M, Gushulak BD, Posey DL, et al. The history and evolution of immigration medical screening for tuberculosis. Expert Rev Anti Infect Ther 2013;11:137-46.

36 Pareek M, Evans J, Innes J, et al. Ethnicity and mycobacterial lineage as determinants of tuberculosis disease phenotype. Thorax 2013;68:221-9.

37 Click ES, Moonan PK, Winston CA, et al. Relationship between Mycobacterium tuberculosis phylogenetic lineage and clinical site of tuberculosis. Clin Infect Dis 2012;54:211-9.

38 Zenner D, Zumla A, Gill P, et al. Reversing the tide of the UK tuberculosis epidemic Lancet 2013;382:1311-2.

39 Winston CA, Menzies HJ. Pediatric and adolescent tuberculosis in the United States, 2008-2010. Pediatrics 2012;130:e1425-32.

40 Batra S, Ayaz A, Murtaza A, et al. Childhood tuberculosis in household contacts of newly diagnosed TB patients. PLOS ONE 2012;7:e40880.

41 Cobelens FG, van Deutekom H, Draayer-Jansen IW, et al. Risk of infection with Mycobacterium tuberculosis in travellers to areas of high tuberculosis endemicity. Lancet 2000;356:461-5.

42 Centers for Disease Control and Prevention. Technical Instructions for Panel Physicians and Civil Surgeons. 2014. http://www.cdc.gov/immigrantrefugeehealth/ exams/ti/panel/tuberculosis-panel-technical-instructions.html

43 Posey DL, Naughton MP, Willacy EA, et al. Implementation of new TB screening requirements for U.S.-Bound Immigrants and Refugees-2007-2014. MMWR Morb Mortal Wkly Rep 2014:63:234-6.

44 Sterling TR, Villarino ME, Borisov AS, et al. Three months of rifapentine and isoniazid for latent tuberculosis infection. N Engl J Med 2011;365:2155-66.

45 Reichman LB. The U-shaped curve of concern. Am Rev Respir Dis 1991;144:741-2. 